\title{
4
}

\section{Grief and Loss in Elementary School-Age Children}

\section{INTRODUCTION}

The physical, cognitive, character, and spiritual development in elementary schoolchildren (ages $5-10)$ is rapid and remarkable. Social influences such as poverty, adequacy of schools, and parenting are examined for their ongoing power in molding the child's present and future. This chapter details how grief and loss due to death, as well as due to limited socioeconomic resources, affect elementary school-age children. The effectiveness of organic supports such as teachers, counselors, and coaches are emphasized. The growing number of children considering suicide at this young age is discussed, and the impact of adverse childhood experiences (ACEs) is explicated. Maturational losses such as parentification, loss of magical thinking, and anxiety are all addressed, and interventions such as progressive muscle relaxation, play therapy, and mindfulness-based stress reduction are identified as useful for work with children.

\section{OBJECTIVES}

After studying this chapter, the reader will be able to:

- Describe the cognitive, biological, psychological, social, and spiritual development of children from age 5 and entry into school to about age 11.

- Understand factors that affect levels of risk for children and their futures as well as protective factors that help enhance resilience.

- Explain the ways schools' practices affect child development, as well as their vital role in promoting health and well-being among bereaved children.

- Understand the way dual process and continuing bonds may be expressed by elementary school-age children. 


\section{VIGNETTE}

Douglas was trying to behave, but he was very angry. They were having to move, once again, and this time it was to his grandmother's, far away. His dad was in jail again, and his mom was getting evicted from the fifth apartment they had lived in since he was in kindergarten. Douglas was most upset because now that he was in third grade, he often got to stay with his cousin's family when his mom was working. After the move, he would not get to do that because they would be 4 hours away. His teacher and his mom did not understand why he was so grumpy-he was not sure he understood it all himself. He knew he was angry and scared. He was sick of his mom telling him it would be "a new opportunity" and that he would have lots of pets to play with at his grandmother's. He wondered if it was even worth studying for his spelling test when he would not be at this school anymore. He had always loved his school and classmates; they all stayed the same even when he and his mom moved to different apartments, but now, even that would change. Douglas knew that no amount of being angry was going to change his mother's mind, but being angry seemed all he was able to do.

\section{DEVELOPMENTAL TASKS: INITIATIVE VERSUS GUILT AND INDUSTRY VERSUS INFERIORITY}

Children usually enter the school environment at about age 5, when they start kindergarten. Until recently, kindergarten allowed a gentle transition from the home environment to an academic setting, but now kindergartens focus on explicit skill and knowledge acquisition. For some children, this is a first exposure to large-group situations; for others, day care or "pre- $\mathrm{K}$ " has socialized them to be part of a large group of children. During early elementary school, children begin to develop confidence in taking the initiative to move out into the broader world, using language skills and imagination to engage with the greater society (Erikson, 1959/1980). Yet some children arrive at school angry about the attention and care they have not received from caregivers and can be extremely disruptive because they have not learned to cooperate with teachers and classmates. In kindergarten and first grade, children begin to leave home for long stretches of time and must perform in different ways from home, where they have (ideally) been nurtured and loved without pressure. For children who have not been in quality day-care settings, these new responsibilities constitute a major transition. Children may experience a loss of positive self-image as they move into the school environment, where peers and teachers judge how well they fit.

Elementary schoolchildren thrive on structure and stability, particularly in their younger years. Neuropsychiatrist and pediatrician Dan Siegel describes this as a time when children learn to navigate between chaos and rigidity and between impulsivity and inflexible adherence to rules (Siegel \& Bryson, 2011). Children at this age need help processing their emotions; they must learn to adapt to circumstances, build empathy, and increase their ability to attend to their own well-being (Siegel \& Bryson, 2011). Douglas had a chaotic family life, and the moves threatened his stability. Although his mother was trying to assure that he had a place to live, she was moving him away from his school and extended family, where he had found some degree of stability and predictability. Leaving an elementary school where people knew and liked him felt very scary. Frequent moves from schools can place children at risk for poor self-regulation and academic outcomes (Friedman-Krauss \& Raver, 2015).

Children who have had unpredictable environments or have not received love and unconditional acceptance from caregivers may find school a haven, where achievements lead to praise and an increased sense of self-efficacy. As children move into the higher elementary school grades, they industriously learn and produce projects and papers and engage in creative, athletic, and other endeavors. The ability to produce in this way promotes a sense of mastery, but the child who is unable to meet this level of industry often experiences a sense of inadequacy and inferiority 
(Erikson, 1959/1980). Ultimately, children who meet the social and academic expectations of the school environment will likely thrive in the social world that will encompass their future.

\section{Biological Development}

Children nearly double their weight and height between the ages of 5 and 11. Fiftieth percentile 5 -year-olds weigh 42 pounds and are about 43 inches tall. By age 11, a child in the 50th percentile weighs 82 pounds and is 57 inches, or nearly 5 feet tall. At the same time, the brain becomes more complex. Children's brains show growth in the prefrontal cortex as well as the temporal and occipital cortices (Sowell et al., 2004). Sowell et al. also found changes in the relationship between gray matter and white matter in the brains of children as they age from 5 to 11 . Some of these changes were highly correlated with the development of verbal skills and are believed to indicate more complex connections that permit higher cognitive skill development and further learning.

Lenroot and Giedd (2006) identified the prefrontal cortex as the site of children's growing ability to control impulses, make rational decisions, and integrate the brain's activities. These abilities are often called "executive functions." Research indicates that children who have experienced abuse/neglect have a $17 \%$ smaller (by area) corpus callosum (the brain structure that helps integrate both sides of the brain) than nonabused children (Teicher et al., 2004).

Brain development and impulse control are critical to the ability to learn, to interact appropriately in social settings, and to develop peer relationships. When the biological substrate (the brain) is not developed, children are at a great disadvantage. The typical school environment requires an ability to remain seated, raise one's hand before speaking, and generally think before acting. These are very difficult tasks for a large percentage of 5-year-old children, but they usually master these skills by the time they move into second or third grade, likely because brain development is sufficient. Theories of brain development posit that children's growing ability to learn from previous errors (Grammer et al., 2018) and to cognitively regulate themselves (FriedmanKrauss \& Raver, 2015) are mediating capacities for learning more generally, especially during the first through third grades. Children who have experienced abuse and neglect may have structural and functional brain changes that impair these executive capacities, often in an intergenerational pattern. When children's own parents were neglected or abused, the parents may have difficulty creating an optimal environment for their children (DeGregorio, 2013).

Along with brain structure and function, cortisol (the body's stress hormone) and its management through the hypothalamic-pituitary-adrenal axis (HPA) are known to be affected by chronic stress and trauma (Bevans et al., 2008). Chronic stress during childhood affects the hippocampus, prefrontal cortex, and amygdala, impairing memory, concentration, and executive function in negative ways (Boullier \& Blair, 2018). Research with parentally bereaved children found their cortisol response was blunted, leaving them at higher risk for depression and other health and mental health problems in adulthood (Kaplow et al., 2013).

Biological development also involves genomics. Genetics was once understood as unchanging DNA, either inherited or not, like a gene for brown eyes. Epigenetics now illustrates how genes are turned on or off via methylation due to environmental exposures. Essex et al. (2013) found strong associations between ACEs and gene methylation. In a prospective study, Essex et al. (2013) showed how maternal stress during infancy and paternal stress in the preschool years yielded changes in the methylation patterns of children later in life. Although the science of epigenetics is still developing and cannot always predict outcomes, it seems that stressors (e.g., parental substance use disorders, parental death, exposure to violence, poverty) may all affect children's genomes.

Physical play, another aspect of children's lives from ages 5 to 11 , is important for developing healthy bones and muscles, as well as imagination. Due to a proliferation of video and computer games, and fears for their safety in many neighborhoods, children may have fewer opportunities to use their large muscles, and pundits have expressed concern about the development of 
children's bodies and growing levels of obesity in the United States (Wallis, 2006). Children need physical activity to maintain their health. Touch-whether gentle and nurturing or as playful roughhousing - seems related to learning gross motor skills and may have beneficial epigenetic effects analogous to the thriving of rat pups licked and handled by their mothers (DeGregorio, 2013).

Childhood obesity causes physical effects that can limit children's development and is highly correlated with later development of type 2 diabetes and cardiovascular disease. Subica (2018) notes that obesity rates remain highest for children in African American and Hispanic communities and that although rates seem to be plateauing or even falling, great health risks remain for obese children. Subica strongly supports limiting access to sugary drinks via caregiver supervision (behavioral intervention) and taxation of soda (policy-level intervention), for instance. Caregivers should also limit screen time while increasing vegetable and fruit consumption and physical activity. He suggests community-based interventions to encourage physical activity, even the use of state tobacco tax money to install speed bumps that enhance the safety of outdoor activity.

Poverty weighs heavily on children. It is associated with low birth weight and prematurity in infancy (making school success more difficult) and with poorer mental and physical health (Xue et al., 2005). Child poverty rates cannot be compared across countries due to divergent definitions and methods of calculating poverty. Child poverty rates in the United States have decreased since the Great Recession (December 2007 to June 2009), but they remain sobering and starkly reflect the inequalities associated with race in the United States. Data released by the U.S. Census Bureau in September 2018 showed that while the overall poverty rate in 2017 was $17.5 \%$ (a statistically insignificant change from $18 \%$ in 2016), the $10.9 \%$ rate for White children under 18 was dwarfed by those of Native (31.5\%), Black (28.5\%), and Hispanic (25\%) children. The figures for children living in "extreme poverty" (families with incomes less than half the poverty rate, or $\$ 1,053$ per month for a family of four) were even sadder, with Native (16.4\%), Black (15.3\%), and Hispanic (10.5\%) rates higher than the White rate (5\%) by multiples of 2 and 3 (Children's Defense Fund, 2018).

\section{Psychological Development}

During their elementary school years, children undergo rapid growth in academic ability as the result of improved processing and integrative cognitive skills. Social skills also develop considerably. The ability to navigate academic and social demands has a great positive impact on children's sense of self-efficacy and self-image.

Erikson (1959/1980) posited that in the elementary school years, children must resolve the crisis of initiative versus guilt followed by industry versus inferiority. Although we typically use the language of developmental tasks rather than crises, we still find that children who have difficulty succeeding in school and peer relationships risk developing a sense of guilt and poor self-image. Piaget (1954) theorized that children between the ages of 5 and 7 move from preoperational thought processes to concrete operations processes, which remain with them to age 11 or 12. The preoperational stage is characterized by egocentric thinking and (according to Piaget, though questioned by others) an inability to put themselves in the position of others. They tend to attribute human characteristics to inanimate objects, and magical thinking (a belief that their thoughts can influence events) is strong. Clearly, if a loss due to death occurs, children are at risk if they believe that their hostile thoughts may have caused the death.

By the concrete operations stage, children have more understanding of causation, quantity, and symbolic action. They can take the role of the other and are able to play games and do roletaking activities. Developing language skills allows children to process their thoughts and emotions with others in ways that were not possible previously. If preschool children are often able to grasp the concept of death (Rosengren et al., 2014), elementary schoolchildren certainly seem able to do so. Massat et al. (2008) suggest that elementary school-aged children are often abruptly returned to school after a major loss, disturbing their dual-process oscillation (between restoration 
and loss orientations) as they must stay in restoration orientation to function at school. They suggest that psychological sequelae of loss in elementary school may be related to this abrupt reentry with little help to process their loss. Massat et al. (2008) emphasize the important role of school social workers in the amelioration of children's grief.

Children with learning disabilities (LDs) are particularly at risk for poor outcomes such as lowered self-esteem and efficacy because they have difficulty meeting academic demands. If learning differences are not diagnosed early, children may grow to believe they are incapable of success and their expectation of failure can become self-fulfilling (Lackaye \& Margalit, 2008). At a time of life when acceptance by peers is critical to the sense of self, children with LD struggle with peer relationships and feel devalued in the eyes of their teachers and possibly their parents.

Bitsko et al. (2018) found that the proportions of children diagnosed with anxiety disorders rose from 1 in 28 in 2007 to 1 in 24 in 2011, with indications that these proportions were continuing to rise. They tie some of this to high levels of parental stress. They suggest that helping children to manage their anxiety (rather than avoid triggers) is the most helpful strategy. An intervention called Supportive Parenting for Anxious Childhood Emotions (SPACE) targets the parents of children with anxiety. It helps parents express a belief that children can face their fears, rather than allowing children to avoid what scares them or focusing on children's fears (Hathaway, 2019). By giving children space and support to handle their fears, children learn that they can survive both what makes them anxious and the anxiety itself.

More disturbing is a rise in childhood suicide, which, although still uncommon, is becoming more frequent among children of ages 5 to 11 in the European Union (Kovess-Masfety et al., 2015) as well as in the United States (Sheftall et al., 2016). Suicide among elementary schoolchildren in the United States is most common among Black male children, who typically took their lives by suffocation or hanging (Sheftall et al., 2016). Helping children manage relationship problems with family members and assuring adequate management of attention deficit disorder symptoms are viewed as likely helpful in reducing the suicide rate among elementary school-age children to the low rates previously seen.

\section{Social Development}

Children who have not entered school generally have social relationships that are mediated by their caretakers. Even in school, much of the activity is structured and supervised until the first "recess" at school or the initial unsupervised play date with a peer. This new peer interaction demands enhanced social skills. Learning to take turns, engage in give-and-take conversations, share possessions for the good of the group, and even the ability to name emotions and display attention are associated with success in the first-grade child's future (Rhoades et al., 2011).

Skill with language is an important factor in a child's acceptance or rejection by peers (Menting et al., 2011). Menting et al. found that higher levels of externalizing behavior (aggression, etc.) among Dutch children from kindergarten to 4th grade were associated with poor receptive language skills and peers' rejection. This is important to understanding loss in two ways. When children experience a loss, they have varying ways of expressing their hurt and fear, particularly at younger developmental stages. Younger children may act out aggressively (or alternatively withdraw) in ways that create peer rejection. This then creates a second loss as bereaved children now lose the social support cushion that can promote resiliency (Criss et al., 2002). In later elementary school, this peer network is used more for distraction and engagement with other activities than to verbally process feelings about loss (Christ, 2000). In either case, impaired communicative abilities, or a tendency to act aggressively, will limit bereaved children's ability to mobilize support after a loss, leaving them vulnerable to grief complications. Notably, tightening school budgets and "return to basics" educational policies mean that many children live in school districts where classes are large and educating students is secondary to keeping them off the street and giving only a modicum of needed mathematical and communication skills (Carlson, 2008). These 


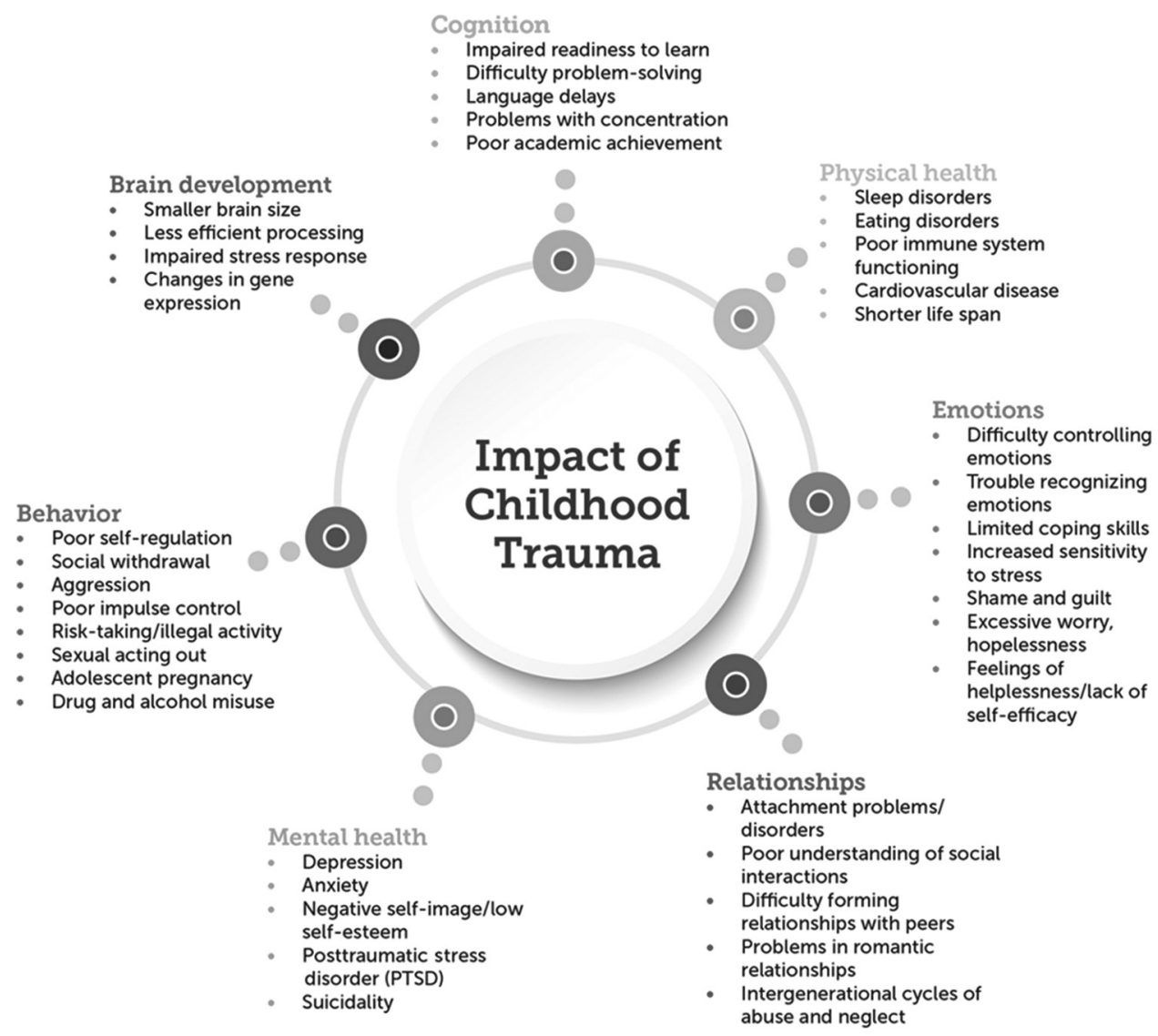

FIGURE 4.1 Impact of Childhood Trauma. This model illustrates the varied impacts of childhood trauma on aspects of a child's development.

Source: Reproduced with permission from Bartlett, J. D., \& Steber, K. (2019). How to implement trauma-informed care to build resilience to childhood trauma. ChildTrends. https://www.childtrends.org/publications/how-to-implement-trauma -informed-care-to-build-resilience-to-childhood-trauma

conditions do not promote the optimal education of students, much less provide the emotional support that bereaved children need.

\section{Spiritual Development}

Children in elementary school become accustomed to learning what adults tell them to learn, and this applies to their spiritual lives as well. In a comprehensive review of research related to children's spiritual development, Mata-McMahon (2016) distinguished between nonreligious spirituality, directed toward transcendence and unity in relationships and/or with nature, and religious spirituality, which entails transcendence beyond the individual into the sacred along with religious stories, dogma, and practices. She observed that studies looking at children's spirituality tend to find that younger children (6-11), even in secular environments, find comfort in a belief in God and tend to pray as a way of finding comfort or expressing desire. Her own research with kindergartners found them being kind, connecting to their environments, and pondering deep questions in ways she defined as spiritual. Further, she notes that Wills (2011) tied spiritual development to music and children feeling as one with something bigger than themselves (chorus), 
hence not requiring religious content. Indeed, definitions of spirituality often draw from Fisher's (1999) classic assertion that spirituality derives from an individual's relationship with four entities: themselves, others, the environment/nature, and the Transcendent (or something beyond oneself). Others note that helping children find quiet in the madness of modern life (Mudge, 2018) or an ability to resist capitalist consumerism (Eaude, 2019) are also critical aspects of enhancing children's well-being through spiritual practices. It seems apparent that children's openness to guidance by adults paired with openness to ideas about the supernatural makes children 5 to 11 ripe for being socialized into religious and other spiritual traditions that will frame their experiences of loss.

\section{SPECIAL CONSIDERATIONS IN RISK AND RESILIENCE}

The increasing number of children born to mothers who used opioids during pregnancy is of great concern. The 2017 National Survey on Drug Use and Health (Substance Abuse and Mental Health Services Administration [SAMHSA], 2018) revealed that about $8.5 \%$ of pregnant women used an illicit drug within the 30 days prior to the survey. Neonatal abstinence syndrome (NAS) following withdrawal of the newborn from opioids has increased between 3 and 10 fold (varying by state) from the early 2000s to 2019 (Brennan et al., 2019). Although there is no clear evidence that these children have specific ongoing medical problems, research to date indicates that children born with NAS have significantly higher medical services usage in each of the first eight years of life (Liu et al., 2019), indicating that they do experience some health impairments. Poorer parenting practices and likelihood of children's removal from parents are associated with parents' opioid use (Winstanley \& Stover, 2019) and these factors may also influence medical services use.

ACEs of all sorts, by definition, happen during childhood and generally entail some trauma. Research suggests that not all ACEs have the same long-term health effects. Dose-response influences (intensity of the ACE or frequency) may function differently. For instance, the more categories of ACEs a child experiences (particularly household dysfunction with emotional and physical abuse), the more likely increased negative health effects are found in adulthood. Additionally, the potency of ACEs such as child sexual abuse may create higher risks for negative health effects in adulthood (Crouch et al., 2018). The dose-response finding indicates the importance of providing remediation of ACEs in childhood and preventing future ACEs (Boullier \& Blair, 2018). Figure 4.1 illustrates the significant negative impact of trauma on children, emphasizing how imperative it is to prevent ACEs and ameliorate their impact when they do occur. Figure 4.2 lists public policy strategies developed by the Centers for Disease Control and Prevention (CDC, 2019a) that aim to prevent ACEs by strengthening economic supports for families and ensuring positive childcare experiences through home visits after birth and accessible quality preschool and after-school programing connected to primary education.

The CDC recommendations rely heavily on educational resources to prevent and ameliorate the negative effects of ACEs. Primary education provides a site where children can have access to adults who can help to ensure their safety and offer support and guidance. Yet inequitable funding of schools means that this potential is often least available for the children who need it most (Baker et al., 2018). When children move frequently, the possibility of developing caring relationships with adults at school is diminished. Research demonstrates that not only do academic markers deteriorate with moving but the mediating role of cognitive dysregulation likely affects many other aspects of the child's functioning (Friedman-Krauss \& Raver, 2015). Good schools with before- and after-school care not only help working parents but allow a haven where children can develop a sense of self-efficacy and meet adults who might identify and/or buffer ACEs. Yet caring, supportive, nondiscriminatory schools can exist only when supported by public policies and funds, a current challenge in the United States. 


\begin{tabular}{|l|l|}
\hline Strategy & Apreventing \\
\hline $\begin{array}{l}\text { Strengthen economic } \\
\text { supports to families }\end{array}$ & $\begin{array}{l}\text { - Strengthening household financial security } \\
\text { - Family-friendly work policies }\end{array}$ \\
\hline $\begin{array}{l}\text { Promote social norms that protect } \\
\text { against violence and adversity }\end{array}$ & $\begin{array}{l}\text { - Public education campaigns } \\
\text { - Legislative approaches to reduce corporal punishment } \\
\text { - Bystander approaches }\end{array}$ \\
\hline Ensure a strong start for children & $\begin{array}{l}\text { - Early childhood home visitation } \\
\text { - High-quality child-care } \\
\text { - Preschool enrichment with family engagement }\end{array}$ \\
\hline Teach skills & $\begin{array}{l}\text { - Social-emotional learning } \\
\text { - Safe dating and healthy relationship skill programs } \\
\text { - Parenting skills and family relationship approaches }\end{array}$ \\
\hline $\begin{array}{l}\text { Connect youth to caring adults } \\
\text { and activities }\end{array}$ & $\begin{array}{l}\text { - Mentoring programs } \\
\text { - After-school programs }\end{array}$ \\
\hline $\begin{array}{l}\text { Intervene to lessen immediate } \\
\text { and long-term harms }\end{array}$ & $\begin{array}{l}\text { - Enhanced primary care } \\
\text { - Victim-centered services } \\
\text { - Treatment to lessen the harms of ACEs } \\
\text { - Treatment to prevent problem behavior and future involvement in violence } \\
\text { - Family-centered treatment for substance use disorders }\end{array}$ \\
\hline
\end{tabular}

FIGURE 4.2 Strategies for Preventing ACEs. This list developed by the Centers for Disease Prevention and Control identifies strategies for preventing ACEs among children along with approaches to assist families in raising healthy children.

ACEs, adverse childhood experiences.

Source: Centers for Disease Control and Prevention. (2019a). Preventing adverse childhood experiences: Leveraging the best available evidence. National Center for Injury Prevention and Control, Centers for Disease Control and Prevention. https://www.cdc.gov/violenceprevention/pdf/preventingACES.pdf

Harvard University's Center on the Developing Child (2019) synthesizes extensive research into three principles designed to reduce risks to children and enhance their resilience and wellbeing over a lifetime: First, support responsive relationships between children and adults; second, strengthen core life skills (including self-regulation and executive functioning); and third, reduce sources of stress for children and their families.

\section{LOSS EXPERIENCED BY ELEMENTARY SCHOOL-AGE CHILDREN}

\section{Impacts and Perceptions of Loss for Elementary School-Age Children}

The developmental processes described earlier have great bearing on how children understand loss and their coping tools. Whereas younger children have few tools for processing a loss and benefit most from the security of a steady and nurturing caregiver, school-age children have a variety of newly developed skills and resources for gaining support and processing the loss. Developmental age and skills define a child's experience of loss, and as children continue to develop, they must rework prior losses using their new, more mature understanding. Children who lose a sibling or parent in toddlerhood will need to rework this loss during later maturational stages 
over their lifespan. As children in later elementary school begin to imagine their futures, they are likely to reexperience their previous losses, realizing that graduations, learning to drive, and so forth, will all happen without the deceased loved one(s). As these secondary losses are recognized, children need acknowledgment and support for renewed mourning from the perspective of the later developmental level, which brings new skills in language, abstraction, and symbolic thought.

Nguyen and Scott (2013) found that bereaved children with higher physical self-concepts (defined as approving of one's appearance) experienced lower levels of depression after a loss. Unexpectedly, they also found that children with a higher math self-concept had increased levels of depression. They speculated that children with high math self-concept may have higher expectations for achievement and that falling achievement in the aftermath of a family death can lead to depression.

Children from ages 6 through 11 tend to express sadness and grief in intense yet rapidly alternating spurts. They may cry one moment and be running around playing the next. Dual process (Stroebe \& Schut, 1999) works somewhat differently in childhood. School-age children seem to modulate their emotions by moving into distraction mode more readily than older people. Although often unnerving to adults, children's oscillation from asking serious and detailed questions about the death to giddy play is a healthy and normal response.

Children in the 6- to 8-year-old group tend to remember appearance-related characteristics and enjoy talking about pleasant memories of the deceased (Christ, 2000; Christ \& Christ, 2006). They benefit from having concrete mementoes of the deceased. They often speak about wanting to die in order to be with a deceased loved one. This is a form of wishful thinking; it is not suicidal ideation (Christ, 2000).

Children in the 9 to 11 age range seem to have a stronger need for factual information and tend to avoid direct expression of emotions, preferring to compartmentalize emotion or experience it very briefly or in private (Christ, 2000). Occasionally, this may lead to aggression or withdrawal. On the whole, children in this age group seem to benefit from interventions that help them remember happier times, obtain a transitional object associated with the deceased, and affirm their tendency to move in and out of emotion about the loss (Christ, 2000). Because memory acquisition and recall are better developed by ages 9 to 11, these children remember abstract qualities (e.g., kindness) of the deceased.

\section{Death Losses}

\section{Death of a Parent}

The death of a parent, of course, is perhaps the most life-changing loss an elementary school-age child can experience. In Sweden, where national registries allow life course analyses of an entire age cohort, Berg et al. (2014) found that parental death had a fairly immediate and significant negative impact on school performance and grades. They theorized that school performance mediates (directly influences outcomes) and moderates (modifies the intensity of outcomes) adult outcomes for educational attainment, substance use, and other mental health disorders known to be associated with parental death in childhood. Later, Berg et al. (2016) found that bereaved children experience somewhat higher rates of hospitalization for depression as they move into young adulthood, with higher risk among those who were bereaved at the youngest ages and those whose parents died suddenly. They suggest that long-term negative impacts of parental death may be ameliorated by attention to children's school performance and enhancement of support for ongoing academic achievement, especially in the first two years after the death.

A study of parentally bereaved children from Denmark, Finland, and Sweden found higher rates of early mortality for the children as they aged, with greater risk when the parent died of "unnatural" causes such as suicide or homicide (Li et al., 2014). Li et al. observed that increased risk can come from genetic heritable sources, epigenetic effects of stress during childhood leading 
to metabolic syndrome or immune system suppression, or social and economic disadvantages after a parent's death. Similarly, Pham et al. (2018) followed bereaved children for seven years in the United States and also found that younger children who lost a parent to suicide, homicide, or other unanticipated death were at higher risk of negative outcomes in adulthood. They noted that depressive symptoms in the first two years after the parental death were common and that a Family Bereavement Program (Sandler et al., 2013) could ameliorate stressors by helping the surviving caregiver provide consistent parenting and support.

Some research indicates that children can experience posttraumatic growth after a parental death (Brewer \& Sparkes, 2011). One person who was 9 when both parents died stated that, at her current age of 19, those losses would "destroy" her; she believed that her younger age at their deaths allowed her to "bounce back" (Brewer \& Sparkes, 2011, p. 211). Brewer and Sparkes (2011) observed that in the United Kingdom, where the study took place, bereavement is spoken of as a journey, in contrast to the United States, where bereavement discourse often emphasizes return to a pre-bereavement state. Children in the United Kingdom may feel free to follow different pathways for coping rather than feeling obliged to "return to normal." In the United States, therapeutic advice for parents raising a child after parental death also asserts that children can thrive after loss if given the chance to honestly talk about their responses in a context of stable support and routines as well as assurance that the surviving caregiver is coping well enough to provide the consistent care the child needs (Borrenson, 2019).

Children envision deceased parents in ways that continue the parent's presence in their lives (Silverman \& Nickman, 1996). Typically, they maintain their connections (continuing bonds) in one of five ways: (a) locating the deceased (in heaven, for example); (b) experiencing the deceased (e.g., believing the deceased parent is watching them); (c) reaching out to the deceased to initiate a connection (e.g., praying to the deceased); (d) remembering (actively); and (e) keeping a belonging of the deceased. Silverman and Nickman see these strategies as critical to the child's coping trajectory. Children who could not "locate" the parent or felt a lack of ongoing connection seemed to have greater difficulty coping over time. They proposed a trajectory of the way children perceived the connection to the deceased parent that moves from (a) seeing the parent as a visiting ghost to (b) holding onto memories of the past, to (c) maintaining an interactive relationship, and finally (d) becoming a living legacy (making them proud, doing well; Normand et al., 1996). Karydi (2018) notes that the surviving parent is most frequently the person who helps children maintain continuing bonds with the deceased parent over a lifetime, and she finds that some adults experience activated grieving for the deceased parent. It seems those children who have help maintaining the continuing bond with the deceased parent find this beneficial in early adulthood, but Karydi suggests that for some, this may also correspond with troubling prolonged grief.

\section{Death of a Sibling}

With the death of a sibling, children not only lose a playmate, confidante, and colluder against parents but also likely lose attention due to their parents' grief. Siblings often believe they must stifle their grief to avoid adding to their parents' sadness or irritability. In a study of adults bereaved in childhood by the death of a sibling, Rostila et al. (2017) found a higher hazard ratio of death in young adulthood for the bereaved, though this was partially explained by the same cause of natural death, especially after removing the half of siblings who died under the age of 1 . They speculate that similar genetic or other pathological processes may affect each sibling and also note that the higher hazard rate of mortality for children bereaved at elementary school age is rather small. Also using a sample from Sweden, Kennedy et al. (2018) measured stress resilience during mandatory military examinations and found that recruits who had a first-degree relative die during their childhood (7-12) had lower stress resilience scores. The scores were worse for those whose relative died during the recruits' adolescence. In short, children's futures seem to be negatively affected by a sibling's death during childhood, yet it is hard to tease out how much of 
this is because of similar susceptibility to illness, changes in the protectiveness of families after bereavement, or lack of supportive intervention after loss.

In examining children's reactions to sibling deaths, Packman et al. observed that schoolchildren generally feel "I hurt inside," "I don't understand," "I don't belong," and "I'm not enough" (2006, p. 830). Feeling that they do not belong or are not enough has to do with changes in the parents as they grieve and transformation of the family structure into something unrecognizable. They feel inadequate to meet their parents' needs and expectations. Packman et al. (2006) suggest that promoting continuing bonds can be fruitful for siblings, although they note the exception of siblings who have had contentious, competitive relationships. They employ the language of Devita-Raeburn (2004), who describes "carrying" the deceased sibling along in life. "Carrying" is a way of keeping the memory and relationship with the dead sibling alive over time.

\section{Death of a Pet}

Commonly, children in this age range lose a pet, often a beloved one that has been confided in and viewed as a family member. This is often the first death a child experiences and may set a template for how the child processes grief in the future. When this loss is disenfranchised through nonrecognition or demeaning or trivializing the feelings of grief, children are given the message that mourning is not acceptable. A similar message is communicated if a beloved pet merely disappears and is never spoken of again. This may detrimentally affect the child's ability to process grief in the future. Pets provide a unique connection and source of comfort (Sable, 2013). When the loss of a beloved pet is acknowledged, children learn that loss can be observed, discussed, and mourned.

\section{Living Losses: Atypical, Typical, and Maturational Losses}

\section{Losses of a Parent(s) Due to Abuse}

In the United States, one in seven children experience physical, sexual, or emotional abuse or neglect each year (CDC, 2019b). Additionally, every 9 minutes, child protective services (CPS) substantiates a claim of sexual abuse (RAINNE, 2019). Children who experience abuse endure the loss of the prior trusting, caring relationship with the abuser and often have difficulty trusting relationships or being vulnerable within them in the future. Experiencing abuse in childhood is associated with intimate partner violence (IPV) in adulthood in complex ways. Physical abuse in childhood is associated with both IPV victimization and perpetration in adulthood. Combined with emotional abuse in childhood, it may be even more strongly associated with IPV victimization in adulthood, though gender of the child and types of abuse affect these associations (Richards et al., 2017).

In adulthood, children who experienced sexual abuse have higher levels of depression, dissociative identity disorder, borderline personality disorder, criminal convictions, substance use disorders, and eating disorders (Friedman et al., 2011), and these outcomes seem to be intensified if the individual is also of sexual minority group status (LGBTQ). Yet we should not forget that many sexually abused children thrive nonetheless (Zafar \& Ross, 2013).

In one of the few studies to examine the narratives of sexually abused children related while they were still children (derived from trauma-focused cognitive behavioral therapy [TF-CBT] interventions), the primary theme to emerge was their fear of the abuser and of experiencing abuse in the future. These fears for safety were written in each of the 21 narratives examined (Foster \& Hagedorn, 2014). Even though most children fear their abuser, they may also continue attempts to gain that person's praise and deny the negative impact on themselves.

Children may lose their parents as a result of CPS removing them from their homes due to substantiated abuse. Christopher Church asserts: 
The research on the harm inflicted by separating children from their parents is so unambiguous that Harvard Professor of Pediatrics, Dr. Charles Nelson, told the Washington Post, "If people paid attention at all to the science, they would never do this." But we do this as a matter of routine in the name of child protection-more than 250,000 times per year. (2019, e1)

Our supplementary materials include a reading from the first edition of this book, in which Tara Sinclair traced the long-term consequences for Nina after her removal from her parents, consequences that included Nina's ongoing attachment problems and difficulty trusting others.

Survivors of childhood maltreatment may deny the effects of the abuse in much the same way that people deny the affective impact of a loss. Just as children bereaved in more traditional ways must rework their losses as they mature, children who experience abuse must rework their understandings to recognize, validate, and grieve the losses involved in the betrayal of the parental (or abuser) relationship or the loss of those relationships altogether if they are removed from parental care. If they deny the negative impacts of the loss, they may be unable to continue to rework their understanding of the experience as they mature. Part of healing and being resilient after losses due to abuse involves acknowledging the experience, considering the losses involved in the parental and caregiver relationships, and attending to self-care and healing over a lifetime. In short, mourning the loss of a trusted caregiver's nurture can be as painful as a death.

\section{Loss Due to Parental Divorce}

Parental divorce is common when children are in elementary school and places children in some untenable positions. Children often engage in omnipotent and magical thinking and therefore believe they somehow caused the problems between their parents and the dissolution of their marriage. Further, they may be used as pawns between parents fighting over property, financial support, and their children's loyalty. Despite the consistent and loud expert advice to help children through their parents' divorce (Hecker \& Sori, 2003), children remain forgotten mourners. The child experiences loss (of the parent who leaves the home and of the former family constellation) but may not quite understand what divorce means. The divorce-related losses of family structure and routine, financial well-being, and assumptive world are powerful. Studies suggest that children whose parents divorce are at somewhat higher risk for relationship instability during their early adulthood, but once changes in economic well-being and parenting problems are controlled for, children whose parents divorce during their elementary school years show few long-term relationship impacts (Fergusson et al., 2014).

Recognizing children's needs for security and stability are keys to intervention. There are few evidenced-based approaches to care for children after divorce, but some note that programs focused on protective factors should be more widely implemented (Pedro-Carroll, 2005). Pedro-Carroll (2005) suggests that support groups allow children to name their own losses and recognize loss and misunderstandings in other children in a supportive environment. Additionally, activities that help children consolidate knowledge about divorce and engage their peers help them normalize the experience. This allows them to get support in validating their losses and promotes resilient adaptation. Sidorsky's reading at the end of this chapter illustrates the deep pain and isolation children could experience in earlier eras when divorce was severely stigmatized.

\section{Loss of Being a Child}

Children can be deprived of their childhood by abuse (of every kind), deaths, the impairment of their caregiver, relocation, poverty, life-threatening illness, or differences like atypical sexual or gender development. Although childhood is idealized and children have more worries, responsibilities, and needs than typically portrayed, many in the aforementioned circumstances become 
parentified: They feel the need to take on the responsibilities, concerns, and burdens of adulthood before their time (Jurkovic, 1997). Although some research finds that parentification can enhance abilities and develop strengths, the general practice wisdom is that families should ensure that children are not burdened with adult roles and responsibilities and that they have room in their lives for play, friendship, and imagination (Chee et al., 2014). Schier et al. (2015) note that emotional parentification can be just as harmful as instrumental parentification (fulfilling adult activities of care) and that depressive symptoms in adulthood are associated with parentification. The losses of parentified childhood are often unrecognized, and losses unrecognized can produce submerged resentment leading to grief later in life (see Sidorsky's observations in both this and Chapter 9 (retirement). Helping families to acknowledge losses and attempt to ameliorate and/or mourn them to some degree may help minimize the internalized rage parentified children may carry into adulthood.

\section{Loss Due to Illness or Injury}

Typically, children are fairly healthy, yet in elementary school, they start to venture from their homes into neighborhoods, schools, and other spaces that are not always as safe as one would wish. Due to playground injuries, especially falls, children between 5 and 9 visit EDs more frequently than people in any other age group (CDC, 2012). As a result of inadequate maintenance, the likelihood of injury is greatest in poorer neighborhoods (CDC, 2012). As the reading by McCarthy illustrates, childhood injuries can have long-lasting physical consequences and hidden psychological and emotional ramifications when children feel different or ostracized because of medical treatments. These are losses of competence, mastery, and the acceptance of peers, in addition to the loss of bodily integrity.

Children sometimes have conditions such as cystic fibrosis and sickle cell anemia that affect them from birth, as well as cancers that develop during childhood. Research and professional opinion coincide in recommending honest, developmentally appropriate communication with children, even those who may still be coming to understand the nature of death. In an extensive review of available guidance in caring for children with life-threatening illness, Bates and Kearney (2015) report that many children are not included in discussions about their health because parents resist hearing physicians' explanations of poor prognoses. They observe that this cuts children off from the opportunity to say good bye, to have adults role-model coping responses, or to have their questions answered and fears addressed. Bates and Kearney report that children in elementary school often fear being alone while ill and worry that they will miss their belongings when they die. They suggest that clinicians help parents understand that their wish to protect their child is understandable but that open, honest, developmentally informed communication will best allow children to receive the support, answers, and reassurance they need to maintain trust in the adults around them.

\section{REACTIONS OF OTHERS TO THE LOSS OF AN ELEMENTARY SCHOOL-AGE CHILD}

\section{Parents' Loss of a Child}

Parents are responsible for the well-being of their children and therefore often have extreme levels of guilt about the death of a child. Rando (1993) asserts that loss of a child consistently correlates with complicated parental grief. The assumptive world is violated when a child dies before a parent, and this leads to a heightened sense of vulnerability.

For parents living through the process of their child's death, the tension between holding on to their child and wanting the child relieved of suffering becomes unbearable at times. Parents 
cope by focusing on action. These have been categorized as piloting, providing, protecting, and preserving (Price et al., 2011). Piloting involves directing the child's care and treatment decisions, while providing involves actual parental care of the child. Protecting the child from knowledge of the illness, caregivers they perceived as less competent, and other real or perceived threats was problematic: Efforts to "protect" in these ways led to communication failures and anxiety. Preserving the family, both during the child's illness and after the child's death, includes preserving the child's place within the family (Price et al., 2011). This implies that helping parents take constructive action can assist them to cope during a child's course of dying. Bereaved parents report that they listen closely to communications from the healthcare team, appreciate guidance about anticipatory mourning and decisions that must be made during the dying process, welcome bereavement support, wish for ongoing contact with their children's care team after the death, and value opportunities to remember their child (Snaman et al., 2016).

In a developed world, children's deaths are viewed as utterly preventable, through either the miracles of modern medicine or vigilance about preventing risks and avoiding accidents. That children will outlive parents is part of the expected order of life. Yet children will always be vulnerable, and a child's death turns the assumptive world upside down. Often, these deaths are totally unexpected and due to tragic accidents. Other times, the deaths are not only unexpected but unexplained, leading to police and CPS investigations that add trauma to the distress of bereaved parents. These bereaved parents have people judge their culpability and assume how they should grieve and cope, which impairs parents' ability to protect their living children from exposures to the details of the sibling's death (Turner, 2017).

Recent technologies such as Facebook, virtual memorials through funeral homes, and other online spaces appeal to some parents, yet they may also work against the North American norm of "moving on" after a death (Mitchell et al., 2012). Despite taboos about discussion of child death, these virtual memorials proliferate. Mitchell et al. (2012) analyze how commercial websites furnish parents with templates to memorialize a deceased child and in doing so both memorialize and reconstitute the child. In maintaining the websites, parents' and others' postings "[transform] the lived experience of their child's death into forms of sociality which include that absent child's presence" (Mitchell et al., 2012, p. 419). The memorial sites seldom include discussion of the child's death and, unlike memorials for stillborn and neonatal deaths, do not include postmortem pictures. Maintaining a sense of the child in the present is a critical feature of the sites. Others' (even strangers') ability to visit the website and virtually "light candles and leave teddy bears," usually at a small cost, eerily reconstitutes the child as a commodity. The interactional nature of these sites whereby parents wish the (dead) child good night, apologize for not writing more frequently, start charities in children's honor, and "share" their child with others creates a public space very different from typical rituals of death. Mitchell et al.s (2012) analysis of "online afterlife" (p. 429) suggests that these sites fundamentally change notions of grief and bereavement to be congruent with continuing bonds (Klass et al., 1996) but also move beyond that with expectations of ongoing interactions.

In addition to continuing the bond with a deceased child, finding some meaning in the death is hypothesized to be a critical feature of parents' grief process and eventual healing. Lichtenthal et al. (2013) explored how meaning-making, benefit-finding, and cause of death interact in parents' grief. Not surprisingly, parents whose children died due to violence had a much more difficult time making meaning or finding a reason for the loss, and fewer than half were able to do so; a small fraction (22.9\%) identified a benefit after the death ("a silver lining" such as growth in empathy or not taking life for granted; Lichtenthal et al., 2013, p. 320). It is important to note that meaning-making may involve consideration of why the death happened, a type of causal attribution, but not always. Sometimes, the meaning may be related to the benefit that came afterward or to a focus on fate. Of parents whose children died of natural causes, $61 \%$ were able to do some meaning-making (an attribution of "God's will," an assertion the child is in a safer place, or an explanation of medical reasons), and benefit-finding was exhibited in more than three quarters 
of their sample. Symptoms of complicated grief were found in both sets of parents but were more pronounced among those whose child died violently.

A particularly challenging form of parental grief comes after a child dies from complications related to a developmental disability. All parents cope with the loss of the idealized child when a baby is born; parents whose child is ill or has a diagnosed disability feel this loss acutely and chronically (Boss et al., 2011). Although prior theories asserted that parents of children with disabilities had "chronic sorrow" (Olshansky, 1962), others contest that (Green, 2007; Morse et al., 2000). Green (2007) argued that the lack of formal and informal support is what aggrieves parents of children with special needs. In a study of mothers whose children with disabilities died, women often felt that their love for their child and their loss were not validated (Milo, 2005). The study found that members of the parents' social network said things like "Don't you think it was for the best?" - a painful dismissal of their child's value. The bereaved mothers in Milo's study had to navigate a reworking of "Who am I now?" once their role of intensive caregiving was lost. Having wished for relief from the burdens of care, but also loving their child and the gifts the child brought, women struggled to make meaning from the conflicted experience. Milo asserted that mothers coped better if they originally were given an accurate portrayal of the child's prognosis and were encouraged to take control where it was possible. Support groups were once again identified as the intervention of choice. Boss et al. (2011) also suggested that parents coped best by identifying the paradox of loving one's child while also feeling burdened, a hallmark of ambiguous loss and chronic sorrow when parenting children with disabilities.

Parental responsibility is unique to the parent-child bond. Couples often are stressed when each parent grieves differently, both due to gender differences and individual coping abilities. These stresses may threaten the relationship if the mutual support between partners is lost at a difficult time when each hopes to be comforted by the other. Instead, guilt may be displaced into blame, leading to further stress in the relationship. Especially when there are questions about the death, parents' tendency to look for blame and occasionally find it in the other may also take a toll on relationships (Turner, 2017). Even so, and despite the commonly held belief to the contrary, divorce is not more common after a child's death (Schwab, 1998).

Parents also encounter an economic toll after a child's death. Research indicates that the costs associated with funerals and time off from jobs for bereavement leave actually pale in comparison to economic costs associated with "presenteeism"-being present at one's work site but not fulfilling duties or being able to work at typical levels of efficacy and efficiency due to bereavement (Fox et al., 2014). Fox et al. (2014) observe that others have found that overall lifetime earnings of bereaved parents are lower than those not bereaved, but it is unclear whether this is due to ramifications of lowered productivity while on the job ("presenteeism") or the result of changes in bereaved parents' work priorities or capabilities that find them assuming less demanding, but lower-paying, employment.

\section{Forgotten Mourners-The Grandparents}

With lifespans extending into the 80s and 90s, many grandparents experience the death of a grandchild. Like parents, grandparents inhabit an assumptive world in which grandchildren outlive both themselves and the grandchild's parents. When grandchildren die, grandparents are believed to experience a double loss in that they mourn the grandchild with whom they often had a special relationship and their child who is bereaved and whom they cannot comfort. Research identifies grandparents as experiencing five aspects of pain: pain from previous bereavements; pain from the loss of the grandchild; the pain of witnessing the son or daughter's grief; the pain of witnessing subsequent negative changes in the son or daughter; and pain that is common to all grief (Gilrane-McGarry \& O’Grady, 2011). Providing support for adult children while mourning a grandchild is clearly stressful. New loss triggers old losses, and grandparents are particularly vulnerable to cumulative grief as they likely have accumulated more losses. It is important to 
remember grandparents when developing bereavement resources following the death of an elementary school-age child.

\section{Losses (Nondeath) Related to Child Protective Services}

Sometimes, parents and grandparents lose custody and care of their children due to their removal from the home by CPS. Nixon et al. (2013) empirically confirmed what has long been assumed: Mothers experience deep pain and grief when CPS removes their children. They explored the particularly fraught situation where children are removed from their mother when there is IPV. Mothers' ambiguous grief over not knowing where their child is or whether the child is being well cared for, and their loss of role and identity as a mother, are so destabilizing that one of the mothers actually returned to her abuser looking for comfort (Nixon et al., 2013). They observe that women's parenting has often been controlled within the IPV-plagued relationship and the removal of children is one more experience of subjugation. Sympathy for mothers who have substance use problems or other behaviors that put children at risk is often lacking; thus, these ambiguous losses are disenfranchised and made more painful. The women need support and validation to process their grief.

Whether from death or removal by CPS, the loss of a child of elementary school age violates parental notions that they should have responsibility for care of their child. Grieving these losses requires revision of the assumptive world wherein the child outlives the parent or will always be with the parent. Further, a parent's responsibility to provide care for bereaved siblings adds additional challenge to that parent's coping. Finding ways of continuing the (revised) bond with the child is critical to moving through such loss.

\section{INTERVENTION ISSUES WITH CHILDREN IN ELEMENTARY SCHOOL}

Children in elementary school are developmentally primed to engage with peers. It is therefore not surprising that many authors describe interventions with children based on group work. Groups allow children to feel the support of others who mourn similar losses. This validates the loss and allows children to hear from others at their developmental level about strategies for coping with their loss. Most important, group participation shows them that they are not alone and that others have gone through very similar losses and circumstances.

As we observed earlier, children grieve differently, taking dual process (Stroebe \& Schut, 1999, 2005) to its extremes; they cry 1 minute and play happily the next, particularly at younger ages. Unfortunately, this makes it seem that they are either grieving "incorrectly" or not grieving at all (Crenshaw, 2002). Children blunt their grief expression in order to protect the surviving parent or siblings from painful reminders and also occasionally due to fears of shaming themselves by showing intense emotions. Clinicians working with grieving children must show themselves as trustworthy, truly hearing and validating the grief, while not pushing or otherwise indicating to children that their emotions should be anything but what they are (Crenshaw, 2002).

Parents generally get bereavement leave (albeit brief), but children are often returned to school fairly soon after a death. It is important to allow space for their dual process to function. For example, assuring that they can leave the classroom to go to a safe space to talk with a trusted adult can help. Linda Goldman, renowned for her work with bereaved children, came to bereavement work from teaching children who had to repeat the first grade. She discovered they often had experienced multiple losses. She used class time to process many of those losses and the children thrived and learned (Goldman, 2015). She advises that bereaved children in elementary school need to tell their story "over and over again" (2017, p. 161); use drawing, storytelling, and acting out the story to project it out of themselves (externalize the problem); have a safe space in 
the school where they can retreat when overwhelmed; be allowed to get "reality checks" in the face of fears about whether surviving family members are safe; and be given the chance to do memory work and create legacy projects. "What we can mention, we can manage" (2017, p. 171), Goldman asserts, creating the expectation that schools provide the environment where children can speak of their losses, document them, and gain support as well as distraction while they build resilience. Clearly, for children in elementary school, help with processing losses must be available in school, and schools need to support learning while children are grieving.

In the case of a parent's extended, terminal illness, decisions must be made about how to prepare for the impending death. Clinicians have moved toward facilitating attachments prior to a death while also acknowledging the coming loss and using time for anticipatory grieving. Saldinger et al. (2004) question the value of romanticizing an anticipated "good death" (2004, p. 916) and also recognize that facilitating intimacy and optimizing remaining time with the family member may be more important than minimizing the strains of trying to both attach and detach at the same time. They studied the effect of this challenging position on children and found that they did make efforts to stay connected to dying parents, even when the parent was nonresponsive due to illness or acted in a "mean" manner (pp. 926-927). They also found that the surviving parent usually bore responsibility for mediating the relationship between the dying parent and the child to some degree, including participating in legacy projects to maintain memories and connections after the other parent's death. Saldinger et al. (2004) found that the unpredictability of death creates problems when families believe they can orchestrate a positive farewell ritual, particularly for young children who may be frightened by the physical sounds and actions of individuals as they die. They conclude that a formulaic approach to fostering attachment is not useful, but fostering attachment is valued when all parties pursue it flexibly and with sensitivity to the child's needs and developmental capacities. Similarly, in pursuing legacy projects, adults should let children adjust their level of interest at any point in time. School-age children seem to avoid attending to letters and other communications from the deceased parent, preferring to look at gifts from that parent or other mementoes. In time, they become mature enough to handle the direct communications.

Intervention strategies to support children with dying relatives tend to be organized to allow professionals to intervene. A professional who is not part of the family system can interact, sometimes in displaced and symbolic ways, to convey information appropriate to the child's developmental stage, correct misconceptions due to magical thinking, validate the child's feelings and responses, and provide support. The clinician can also help interpret some of the child's behaviors to family members to reduce reactivity and correct misunderstandings. Saldinger et al. (2004) recommended that children and families with a dying parent need provision of information, communication of feelings, promotion of awareness and responsiveness, maintenance of a stable environment, assuring additional support for the child, exposure to the dying parent, encouragement to participate in funeral arrangements, relationship facilitation, and meaning-making. Clinicians in palliative care and hospice have long known that accurate communication with children is critical to their resilience. Even so, a review of extant articles about professionals delivering such care shows that while they aspire to deliver family-focused care, they often shy away from explicit communication with children (Franklin et al., 2019). They often felt unprepared to seek out the children, to understand their developmental needs, to manage their own empathetic and emotional responses to the entire family, and to manage the stresses within the family and the healthcare team as the parent was dying. Franklin et al. observed that these professionals understand the importance of providing such care and supporting the bonds between children and their parents. They recommend that employers and agencies assure appropriate support for the workers themselves so that they can adequately provide support (Franklin et al., 2019).

Play therapy (Boyd Webb et al., 2011) and mindfulness techniques (Burke, 2010) are also commonly used with bereaved children. Play therapy allows children to play out the story of the loss or to engage in the reworking of it as they express the anger, replay differing outcomes, or use the play to ask questions and get correct information from the counselor. Mindfulness-based 
stress reduction and other mindfulness approaches involve training the child to adopt relaxation practices (visualization and progressive muscle relaxation) that help create an attitude of nonjudgmental, patient awareness, sustained and directed attention, and intentional use of the awareness and attention in directed practice (Burke, 2010). In a systematic review, Burke (2010) found that most studies of mindfulness with children in elementary school have focused on feasibility and acceptance of the method rather than its efficacy. Goldman observes, "Today's children face a kaleidoscope of grief and loss issues ranging from school shootings, terrorism, and hurricanes to a parent's deportation, homelessness, or imprisonment. . . . Educators can provide grief vocabulary, resources, crisis and educational interventions, preventions, and 'postventions' in order to create an oasis of safety for bereaved children within the school system" (2017, p. 171). She is right, and children in every school everywhere deserve prepared counselors at school where the children spend the vast majority of their time.

\section{READINGS}

\section{Good Boys of Divorced Parents-Part I: Childhood Differences STEPHEN SIDORSKY}

Stephen Sidorsky, MSW, LCSW, has retired as director of mental health services in community mental health. He is currently a part-time lecturer at Rutgers University School of Social Work and teaches in the Continuing Education Program in Social Work.

\section{PART | of II}

There is, somewhere, an "iconic" photo of a young boy, maybe 6 or 8 years old. His parents are divorced (have been for most of his life), and the young boy lives with his mother. In the photo, he is neatly dressed in a short-sleeved shirt, hair combed, sitting by the window waiting for his father who is coming for a visit. He waits a long time, perhaps for an hour beyond when his father was to arrive to take him out to lunch, perhaps to a movie or even better, to play catch in the nearby park. His father never arrives, and the young boy steps away from the window, walks over to his bed, and sits down to read a book. There is no talking about this with his mother, except to say, "He must have had to work. Maybe he will come another time."

This story is not so much about a particular phase of life and how a loss was experienced, processed, and resolved or integrated. Rather, it is about a particular kind of loss, how it was regarded (or not), and how it infused itself into my life and colored it for many, many years.

In an odd way, my parents were always "separated." They married in the early 1940s, my father was in the service during the war, and I was born soon after his return. From what I understand, trouble started at that time and only got worse. While I never remember them being together, their actual divorce happened when I was about 6. My mother and I moved into my grandmother's apartment, which was in the same building as ours was, in Brooklyn. The important piece to all this is that no one ever said anything about the separation, the divorce, or our move to the new apartment. Nothing was acknowledged, declared, or explained. There would be no "before" and "after," no recognition that something had happened. Simply, father visited less and less frequently, until it got down to maybe three or four times a year, and eventually fewer than that.

I have since learned that this experience illustrates two types of loss and grief: ambiguous loss and disenfranchised grief. The ambiguity comes from (for a young boy) a disorienting and 
worrying sense of not knowing what was happening. In the context of ambiguous loss, the person-my father-was physically absent but remained psychologically present. As his absence was never spoken about, was never acknowledged-there was never an instance of "Let's all sit down-we have something to talk to you about"-I was living in a kind of twilight zone-something profound was happening, but since we never spoke about it, we continued to live as if nothing had happened. On one hand, my father seemed to simply fade away and slowly disappear from our lives. At the same time, in his absence, his presence became greater than when he actually came by and spent time with me. My experience-my sense of loss and uncertainty-was very much disenfranchised, in two ways. For one thing, it was ignored and disregarded, as if nothing was happening. Second, there was the feeling that something was wrong with me because my parents were separated-it was as if I was disenfranchising my own sadness and sense of loss, as no one else really acknowledged what was happening.

Strangely (though not so much in the context of ambiguous loss), I felt his presence was greater when he wasn't there, than when he was. I had no siblings, so the family was myself and my mother. My uncle (her brother) lived nearby with his family, and while there was a closeness between us, I maintained a certain distance-a lifelong avoidance of attachment, fearful of another unspeakable loss.

I think this "loss," occurring when it did and during the time when it did (the 1950s), was particularly difficult for several reasons. Coming from a so-called "broken home," as it was referred to in that era, was an embarrassing, almost shameful thing. It set one apart from the other families in this lower middle-class, Jewish community and set me apart from most everyone else. Divorce was not as acceptable as it is today. While there were probably others like me, I knew of only one other person-another boy-whose parents were divorced. Not that he and I commiserated or shared stories. We couldn't as I did everything I could to keep this shameful thing a secret.

Another aspect was my age when this was happening. That 6- to 9- or 10-year-old period is one when you begin to step away from the security and familiarity of family and move into a world of peers, school, playgrounds, and, in my neighborhood, hanging around the candy store. It became difficult for me, given this secret I was carrying around, but also because a part of me felt I needed to stay at home, lest it fall apart even more than it already had.

This loss-or rather, my efforts to maintain this secret-was the central feature, the absolute organizing principle in my young life. From it came my shame, my guilt, the lens through which I viewed the world, understood families, relationships, one's place in the world-whether you "had it" or didn't have it. You were either a "normal person" or you were damaged. Once branded, labeled, classified, and cataloged, that is who you were; you could never really shake it off, or even if you were to, it followed you like a shadow always there, regardless of what you said, how you looked, or what you did, not unlike Hester Prynne's Scarlet Letter. Yet, if she chose to, she could have torn it off, moved away, and started over. Mine was more like the mark of Cain, except that nobody could see it. While I realize now that it was my choice to wear this invisible tattoo, there was no one to talk to about this and no one to show me how to let it go. It was not a question of making a choice-it simply was.

The experience of such a loss (or better, destabilization or disorientation) at such a time in my life-when I was beginning to make attempts to "separate" and develop connections with others outside of my small family-deeply affected how I related to others and structured my relationships and my activities. As my parents were always at odds (regardless of whether my father was "present" or not), I was always "in the middle" or at least felt that I was. Like many children in this situation, I frequently felt a sense of guilt and responsibility for how our life had turned out. Children often believe that somehow it is their fault that their parents are not able to live together or even to get along.

"If only I could be more like this, less like that, my parents would come back together, and we would be a normal family."

While I do not mean to pile on more and more of what led to my experience, I should mention that it was not only in my home that things were ignored. For whatever the reasons 
were-perhaps I feared being told that I just was not wanted-I never asked my father why he left, if he was ever coming back and, later, why was he visiting less and less, until he just disappeared (when I was about 13 years old). Though I was not aware of this at the time, the impact of no one acknowledging the situation made it more and more difficult and painful to go about the day-today business of growing up.

I was not really aware that I felt responsible for this situation. But in the end, I guess I did, since, after all, I did feel that something was wrong with me. Otherwise, why did I carry with me the feeling and belief that no one really wanted to be my friend and that if someone chose me for something, they were doing it so as not to hurt my feelings. This was a feeling I carried for many years, even though I knew it was a distorted, untrue picture of things.

In many ways, I was not really aware of my experience as "a loss." Perhaps if I could have understood it in such a way, even by naming it as a loss, I would have been able to understand it as something that had happened in my life, rather than as the core of my being and who I was. I carried the sense of simply not being "good enough" throughout most of my young adult and adult life. For example, I was very aware of my wish to have a mentor, a guide, a kind of father figure who would help me along. Even so, when I had the opportunity-in summer camp with my counselors, some teachers in high school and college, supervisors, trainers, and directors, who were older than I, at jobs, even therapists that I saw-I both hungered for them, but at the same time eluded their attempts to be helpful. The vulnerability, the fear of being disappointed or abandoned, and, perhaps more than anything, the belief that they were only being "good to me" out of some kind of sympathy always stood in the way.

My growing awareness of this dynamic enabled me to benefit from these mentoring relationships. I made a conscious effort not to dismiss them, but rather to engage and to try hard to be open to what they offered me. In some cases, it worked, in others, not so well, but over time, things became better for me. The core belief remained, however, and was probably strongest when my wife and I considered having children. I truly wondered if this was something I could manage. The good news is that I did manage, and I continue to do so.

So, an important note in thinking about separation and divorce and children: Remember the importance of being open and honest (to the degree that one can) with a child or adolescent, even if it might seem that what you are discussing is awful, heart breaking, or impossible to live with. This does not mean spilling an unfiltered story all over the place, but rather, that talking about things is better than leaving them shrouded in mystery.

\section{Fun and Fall Affect the Future: Childhood Injury's Unseen Losses CAITLIN MCCARTHY}

Caitlin McCarthy, PharmD, is a clinical assistant professor in the Department of Pharmacy Practice and Administration at the Ernest Mario School of Pharmacy, Rutgers, the State University of New Jersey. She maintains a clinical practice site in ambulatory care at Henry J. Austin Health Center, a Federally Qualified Health Center in Trenton, New Jersey, where she also serves as the director of pharmacy services.

I lost 2.5 vertebrae-part of thoracic vertebra 2 and all of 3 and $4-$ when I was 11 years old. Though this loss was only a few millimeters in length, it turned out to be one of the most impactful losses of my life.

One day after school in late spring, I, being the silly and adventurous child I was at the time, thought it might be fun to climb the tree in my front yard. This was at the start of a thunderstorm. While my younger brother rode his bike back and forth in the street, I attempted to pelt him with 
berries that grew from the tree branches. This soon turned into a full-on berry war. Looking back, imaging the scenario, I still think it would have been a lot of fun had it not been interrupted. However, in an unfortunate turn of events, I took one wrong step, slipped on a particularly slimy bit of sap, and fell down from the tree, landing directly on my back on a piece of root that stuck out from the ground.

The wind knocked out of me; it took a moment to collect myself. I looked up from the flat of my back to see my brother standing over me, staring down with an uncharacteristically shocked look. I had never seen him look that concerned. In a moment of panic, thinking something dreadful must have happened, I stood up and ran into the house to inspect myself. I played quite a few contact sports during my childhood, so I was no stranger to injury. After a quick once over, I deemed the situation to be minor and decided this was not something worth telling my parents. However, a day or so later, I did notice that my back seemed to hurt more than I had originally perceived. It was painful, yes, but it still seemed manageable. It took about a week for me to realize that this was a far more serious injury than I had originally assessed. I vividly remember being in my kitchen, looking up at my mom, and telling her that I thought something was wrong.

The next week, I saw my pediatrician, and three more weeks elapsed before I saw an orthopedist. One MRI later, I was referred to an orthopedic surgeon who happened to be the same doctor who performed surgery on my brother 1 year prior. From the MRI, it was clear that part of my spine had collapsed on itself, but it was not just due to the fall. After two more imaging studies, I finally had my diagnosis. I was told I had an eosinophilic granuloma. I sat next to my mom as the doctor described my disorder. I remember trying to memorize the name, sounding it out phonetically over and over again, E-OH-SIN-OH-FILL-ICK-GRAN-YOU-LOW-MA, while trying to keep up with what my doctor was saying. He said I needed surgery. He said that my tumor was in a difficult location. He said that some aspects of the surgery were experimental. He said they would need to collapse one of my lungs to do the surgery. He said there was a low chance of complication. He also said that I could die. He said that my vertebrae might grow back. He said that I could hope for my vertebrae to grow back by fifty percent. He said there was nothing we could do about the vertebrae themselves except to hope for recovery. It felt a bit surreal when the doctor faced me to ask what I thought. I recall thinking it strange for him to ask a child for permission to perform such a procedure. While I understand now that my parents also had to provide consent, it was both intimidating and empowering to be asked, and I agreed to the surgery.

An eosinophilic granuloma is a benign, solitary tumor of bone. It strikes me as a bit odd to call what I had benign. From a medical perspective, of course, it makes perfect sense. My tumor was not malignant; therefore, it was benign. However, it did not follow the standard definition. My illness was not kind, nor was it friendly. It certainly was not benign.

The summer during which most of the diagnostics occurred were something of a blur. Most of it was spent in doctors' offices, completing tests, and preparing for surgery. While this took away from my usual summer entertainment, I was so focused on finding out what was wrong that it did not bother me much. However, the events of that summer changed me. Prior to breaking my back, I was considered by most of my family and friends to be something of a wild child. I was filled with energy and constantly on the move. The pain I experienced and the thought of surgery tempered my disposition. I became more serious and more withdrawn. However, the most striking changes came after my surgery.

My surgery was performed about 1 week prior to the start of sixth grade. For months after, I felt delicate, a feeling with which I was not very comfortable. It was frustrating. I was no longer an invincible child. Recovery was a struggle. Collapsing my lung for the surgery took a toll. I spent each day exercising my lungs with an incentive spirometer, but it was nearly a year before I felt like my stamina returned. Worse than that was the pain. Going into the surgery, I had an expectation that my pain was primarily due to the tumor, and after its removal, I would feel better. Instead, my pain became excruciating. For the first few weeks, I could not sleep in my own bed. Instead, I would attempt to sleep upright in the reclining chair in my father's work room. The pain kept me 
awake. I would spend hours willing myself to sleep. Nighttime crying episodes became habitual. They would begin a few hours after my three siblings and parents had gone to bed. The first few nights, I cried uncontrollably, and each night, my mother came downstairs to comfort me until I was too tired to keep my eyes open. Later, I had more control, and I would wait as long as possible until I felt like I was starting to feel insane from the pain and exhaustion. In retrospect, I now know that part of the reason I was crying was due to loneliness. I did not want to have to suffer alone, and I craved the feelings of security that my mother offered. However, one night when I cried, she did not come. The next night, I moved myself back to my bedroom.

I shared a room with my sister and tried to stay quiet out of respect for her. I remember many sleepless nights lying in bed, turning to my side, staring at my wall and wondering "Why? Why did this happen to me? Why does it hurt so much? Why can't I get better? Why am I so sad? Why am I so angry? Why does no one seem to notice? Why can't I just die?" Years later, my sister explained to me that it was in that time that she first noticed my depression.

Going to school soon after my surgery also proved to be a challenge. To help ensure as much growth as possible, I needed to wear a back brace. While I waited for my permanent brace to be constructed, I had a temporary brace that was more like a corset and fit discretely under my shirt. I do not think many of my peers noticed. That changed when my teacher started roll call. When she came to my name, she asked me to confirm that I was the girl with the medical condition who needed the special desk. As someone trying to draw as little attention to myself as possible, the feeling of all eyes on me left me literally speechless. I started to shake my head back and forth. She pressed on, pointing to the large drafting desk that had been set alongside the wall, wedged between two bookcases, and looking away from my classmates. For fear of being ostracized, I lied and told my teacher that she was mistaken. When I did receive my permanent back brace, I realized why the drafting desk would be needed. The sheer size precluded me from using a traditional school desk. It was also clear to me that if I wore my back brace, there would be no way to hide it, and my teacher would realize I had lied. So, instead, I chose not to wear it to school. Somehow this never became much of an issue, something I still wonder about today.

I tried to wear my brace as much as possible when I was at home, though it was very painful and limiting. One weekend, I went to a close friend's house for a sleepover and brought it with me. After hours of being mocked mercilessly and trying to laugh off the insults, my friend fell asleep while I silently cried next to her. I became much more guarded in our friendship after that night. I realized that, for better or worse, she put a large emphasis on appearance. Having very little interest in appearance myself, and certainly no interest in using appearance as a tool to insult others, a wedge was placed between us. While we have grown somewhat distant over the years, we are still friends to this day, so much so that we were in each other's bridal parities. However, that night allowed me to see that though I did not care about my physical appearance, I was very much concerned about how others viewed me in general. I decided to never again wear my brace in front of nonfamily members.

One of my greatest embarrassments was the toll my injury took on my performance as an athlete. Though I played many sports as a child, one of my favorite activities was to play soccer. I started playing when I was 5, and as far back as I remember, I played year-round. My parents and I put a lot of effort into the game, with weekday practices, weekend games and tournaments, offseason private training sessions, and soccer camps.

The year prior to my accident, I tried out for and made a traveling soccer team. Though I loved the game, I never thought of myself as a particularly gifted player and making the team seemed to validate all of our efforts and filled me with immense pride. My injury served to be a huge setback to any progress I had made in that first year.

I attended every practice and put more effort into my training than I had ever before, but no amount of effort seemed to overcome the effect my injury had on my performance. As I recovered, I spent most of my first season back on the sidelines and offering support to my teammates. 
My coach gave me the opportunity to play for about 5 to 10 minutes each game, but due to the competitiveness of the league, and my underwhelming performance, I never played in both halves. While unsatisfying, I was relatively at peace with this. I understood that I was having a negative effect on my team's overall performance, and typically, 5 minutes of running up and down the field was all that my back could handle. However, my father did not seem to share my sentiments. One game during half time, my father had an unpleasant conversation with my coach about how little I was playing. I had already played about 10 minutes during the first half, but my father said we would leave if I was not allowed to play in the second. My coach listened to my father and had me start the second half. Five minutes in, I was in excruciating pain, came to the sidelines, and asked the coach to substitute me out. At that moment, my father came to our side of the field and started screaming at the coach for taking me out of the game, not knowing that it was at my request. The coach attempted to defend himself, and when my father learned that I took myself out, he became furious with me, yelling at me in front of my team, the opposing team, and the spectators. To be in that incredible amount of pain, to want nothing else but to be able to perform as my former self, and then to have someone I trusted to support me unconditionally seem to have absolutely no regard for my well-being and humiliate me-it was heartbreaking. I knew my dad had a powerful competitive streak that showed itself that day, and I knew he was trying to advocate for me, but he added literal insult to injury, and although I knew he loved me, I felt devastated.

One thing that makes me grateful for this experience is how it nurtured my passion for music. I never received any formal counseling. Instead, music was my therapy. Breaking my back may have had a significant negative impact on my athleticism, but through that loss I was able to find something else that filled me with a sense of accomplishment. In a time when I felt delicate and helpless, there was still something I could control. I would lose myself for hours playing piano after school and on the weekends. One of my favorite days was when my grandparents took me to pick out a piano of my own, the same piano that sits in my living room today. It has been nearly two decades since my fall, and playing the piano continues to bring me a unique sense of joy and peace.

My back is still broken. Soon after graduating from college, I had a follow-up MRI when my pain was flaring. The good and bad news was there were no changes. My spine did not get any worse, but it also did not grow back the $50 \%$ that I had anticipated. I experience daily painunremittingly. As to be expected, it waxes and wanes with some weeks harder than others. I often wonder what it would be like to have just one day when I did not experience pain. I think about what I might be able to do if I did not have to live with chronic pain. More than anything, I think about how a life without pain might affect my mood, my energy. Would I feel more confident and have more patience? Or is being shy, insecure, and irritable innate to my personality? Would I feel less sorry for myself? Would I feel as depressed or anxious? I have many unanswered questions, the most lingering of which is why do I feel so ashamed to expose my vulnerabilities? People who know me do not think of me as shy, insecure, or depressed as I work each day to project the persona I want to be. I like to think of myself as being strong. "Tough as nails" is how my high school cross-country coach described me once after hearing about my condition, and I like to think I live up to that description.

\section{Matty's Death and Emmy's Life With Li-Fraumeni Syndrome ALLISON WERNER-LIN AND CATHERINE WILSNACK}

Allison Werner-Lin, PhD, LCSW, is associate professor in the School of Social Policy and Practice at the University of Pennsylvania and a licensed clinical social worker in private practice specializing in bereavement and oncology. She serves as senior adviser to the Clinical Genetics Branch of the 
National Cancer Institute, where she oversees psychosocial research on hereditary cancer predisposition syndromes.

Catherine Wilsnack, MSW, LMSW, is a recent graduate of The School of Social Policy and Practice at the University of Pennsylvania and a licensed social worker with specializations in aging and research. She is a predoctoral fellow at the Clinical Genetics Branch of the National Cancer Institute working families affected by Li-Fraumeni syndrome (LFS) and inherited bone marrow failure syndromes.

Li-Fraumeni syndrome (LFS) is a rare cancer predisposition disorder caused by mutations in the TP53 gene. The mutation is inherited in an autosomal dominant fashion, meaning each child of a carrier parent has a $50 \%$ chance of inheriting the variant. LFS is characterized by nearly $100 \%$ lifetime penetrance, with syndrome-related cancers occurring from childhood through older adulthood. Multiple, independent, primary malignant tumors often occur in the same individual, with the highest risks for soft-tissue, bone, breast, brain, and adrenal cancers, as well as acute leukemia (https://rarediseases.info.nih.gov/diseases/6902/li-fraumeni-syndrome). Recommendations for early detection for all genders are rigorous: frequent regular physical examinations, whole-body and brain MRI, abdominal and pelvic ultrasound, and breast cancer screening starting approximately age 20. Comprehensive screening protocols do result in earlier diagnosis, but the impact of regular screening on survival has not been quantified. Recommendations for prevention include bilateral risk-reducing mastectomy for women. Families often experience multiple concurrent diagnoses, both within and across generations, leading to high cancer burden and substantial physical and emotional distress among family members (lfsassociation.org).

\section{The Case of Emmy}

Emmy is a bright, curious, 8-year-old with LFS. When she was a toddler, her older brother, Matty, experienced severe and debilitating headaches, blurry vision, and disruption to his balance. Rebecca, their mother, "had that parental instinct that something was wrong." A visit to the pediatrician escalated rapidly to consultation with the ED, discovery of a brain mass, and surgery to excise a medulloblastoma on his brain stem. The nearest comprehensive cancer center equipped for surgical and chemotherapeutic treatment was a 4-hour drive from their home. For the following 6 months, Emmy lived primarily with her father, Fred, at the family's home, while Matty and Rebecca stayed near the hospital to enable his care. Rebecca described "going into Emmy withdrawal," so Rebecca and Fred would swap parenting roles 1 week per month. Rebecca was "torn, so much. But you get into the mode where you do what you have to do."

After Matty's surgery, Fred contacted a distant cousin to learn more about the family's medical history. This cousin was the sole surviving member of his branch of the family tree; the rest had died of various rare cancers. Fred suspected a genetic component and made an appointment with a genetic counselor at the facility where Matty was receiving treatment. The genetic counselor took a multigenerational family history and suggested genetic testing was indicated, but Fred and Rebecca were too overwhelmed with Matty's treatment to proceed. Instead, they had Matty tested 6 months after he finished treatment and confirmed that Fred and Matty both carried a TP53 mutation linked to LFS. After consulting with the oncology social worker, Rebecca and Fred "waited to have Emmy tested" because they "honestly just couldn't handle the information."

Matty's paternal grandmother, also TP53 mutation positive, was diagnosed with cancer just after Matty. This timing impacted how Rebecca and Fred shared Matty's LFS diagnosis with her, "because she felt guilty, and she was starting her treatment, and not in a really good emotional state. So, we waited because you can only take so many blows." Eventually, Matty's optimism inspired his grandmother to find a purpose in her own struggle. She would say, "If my grandson can 
go through chemo and radiation, then I can, too." Their concurrent treatments, however, left Fred emotionally and physically exhausted. With his mother and son in simultaneous cancer treatment for cancers related to a syndrome with which he was also diagnosed, Fred experienced "every little ache and pain, first thing that goes across my mind, 'Could this be my first [cancer]?"'

Over the next 14 months, Matty's doctors identified and excised two tumors during regular follow-up surveillance. To maintain as normal a life as possible for Emmy during this time, Rebecca and Fred "isolated her from some of the worst. She didn't have to see all of the treatments that he had." While their parents were at the hospital for Matty's surgeries, Emmy often stayed with an older neighbor who gave her vague information about what was happening with Matty's care or when her family might return. This left Emmy confused about what was happening to Matty. She missed playing and laughing with her big brother.

\section{End of Life}

At a regular surveillance visit, which the family entered "expecting it to be another regular 3-month checkup," physicians discovered Matty had a glioblastoma that was ultimately terminal. Rebecca and Fred were not "ready to just give up" and enlisted Matty in a clinical trial on the east coast that gained him " 8 months of quality ...; [he] was walking again, back to school full time, getting straight A's, the tumor was shrinking." However, once the tumor grew into his brain stem, "he lost his vision, his hearing, he couldn't swallow anymore, and then he was done."

Matty entered hospice. The hospice social worker, Annie, discussed Matty's end-of-life care decisions with Rebecca and Fred. They struggled to share Matty's terminal prognosis with him and with Emmy because they "didn't want him to lose hope." Using a psychoeducational approach, Annie provided a safe holding environment for Rebecca and Fred to anticipate Matty's death, for Fred to consider his guilt, and to invite discussion with Matty about his wishes. They also needed to discuss the present and future needs of the family's hidden patient, Emmy. Matty died at the age of 13, when Emmy was 10. At the time, Emmy did not understand how Matty could "give up" on what the family referred to as the "cancer fight," and leave her. Through art and play-based therapy, Emmy asked questions about Matty's death and learned more about his end-of-life experience.

\section{Testing Emmy}

A year later, Rebecca and Fred decided to pursue TP53 testing for Emmy and were devastated to learn she carried the same mutation. Rebecca referred to Emmy's diagnosis as belonging to "part of the mutant branch" of the family. "Having to tell Emmy was pretty tough." Emmy started to ask more questions about Matty's death when she began regular screening at age 11, "So that was very real to her when she realized she had to start that process."

Emmy's LFS diagnosis complicated her grief over Matty's death. She had trouble adjusting to her new role as an only child. The family felt no reprieve from the grief associated with Matty's initial cancer diagnosis, remission, or death; "knowing that it [cancer] could happen to Emmy at any time, weighed us down." Rebecca sought counseling for Emmy and for herself, "the only nonmutant in the family." Fred and Rebecca considered every change in Emmy as a signal of cancer. "She had a bout of high fever last year, and we had to have her blood checked every day for five cause her white cells were crazy. All I could think about was leukemia."

Rebecca also took comfort in phenotypic similarities between Fred and Emmy, saying Fred has "a really strong immune system. He's never sick. And Emmy's the same way, which gives me hope that she'll be where he is today, with no cancer at 49."

Though Emmy initially did not want to talk in a group setting, Rebecca persisted in seeking out resources to support Emmy, because "whenever we would start talking about Matty, she would leave the room." Rebecca found a social worker, and the family started to see her regularly in various configurations to grieve Matty's death, learn to live with Fred and Emmy's risk, address 
Rebecca's fear of burying them all, and give the family language to talk about their history. After several months, Emmy is cancer free and reconnecting with her memories of Matty. Rebecca reported to the social worker, "Now she talks about him, she's got pictures of the two of them up in her bedroom, and I think she's handling it really well."

\section{Case Analysis}

Working with families impacted by inherited cancer predisposition syndromes requires mental health professionals to attend to multiple forms of grief and uncertainty. The combination of profound grief regarding Matty's death and cancer risk for Emmy and Fred is tied together. Families live in a persistent state of loss and change when living with an inherited cancer predisposition syndrome, which requires ongoing, multimodal, and multidisciplinary approaches to bereavement.

\section{Present Losses}

Emmy and her parents faced multiple losses before, during, and after Matty's death with limited respite. Initially, Emmy lost her brother and mother for the 6 months of Matty's treatment. This loss remained ambiguous (Boss, 2006), as Matty and Rebecca continued to play a significant role in shaping family life yet were often absent from the home for prolonged periods of treatment and surveillance. The diagnosis of Fred's mother further destabilized the family. Others were bodily losses, such as when Matty regained, relished, and then lost physical function in the months leading up to his death. Fred began to experience his body differently after genetic testing as cancer worry grew. Emmy also lost control over her body as she submitted to regular screening protocols that increased family anxiety and triggered memories of Matty's struggle.

\section{Practice Recommendation}

This family would benefit from ongoing medical family therapy (McDaniel et al., 2014) due to the chronic and ambiguous nature of Emmy and Fred's disease risk, the demands of early detection protocols, and the need to balance resources between LFS and activities of daily life. Meaning-making and memory work will help the family adjust to their new configuration, including Emmy's new role as an only child, while remaining connected to Matty's memory. Such work may be balanced with granting permission to enjoy cancer-free, restorative time together, particularly when it includes opportunities to enjoy, rather than fear, their bodies.

\section{Losses Yet to Come}

Much of Rebecca and Fred's distress concerned losses they continued to anticipate. Because inherited cancer risk is unpredictable, families are often biased, affecting their ability to interpret risk information. Emmy may anticipate following the pathway of her deceased brother or her healthy father, both carriers of the familial mutation. Like Rebecca and Fred, parents are often responsible for disclosing and discussing cancer risk with children and setting expectations for how the family will discuss loss, risk, and survivorship. These conversations are often challenging due to feelings of guilt at having "passed on" the mutation, yet prompt disclosure generally strengthens trust and cohesion between parents and children.

\section{General Practice Implications}

We recommend that parents structure ongoing conversations tailored to the child's developmental, cognitive, emotional, and behavioral abilities to support comprehension, and urge parents 
to revisit these conversations as children mature. Best practices show that experienced genetic counselors (www.nsgc.org/findageneticcounselor) and mental health providers can guide parents through these conversations (Werner-Lin et al., 2018).

\section{Supporting Emmy}

Emmy sustained different losses than her parents, primarily the loss of an only sibling and the promise of a healthy future. After the death of a sibling, children often fear their own death, experience somatic complaints as bids for attention or as a mechanism to communicate with caregivers, and may lose their sense of security in the world. For Emmy, these feelings are intensified due to her shared LFS diagnosis. Since she is younger than Matty, her grief and cancer worry are likely to intensify as she reaches the age Matty was diagnosed and died. A holistic plan of support for Emmy will entail cognitive behavioral interventions to balance magical thinking with survivor guilt. Psychoeducational interventions may help Fred and Rebecca recognize the idiosyncratic ways children like Emmy grieve so they can interpret and respond to her needs. Integrating Rebecca and Fred, who are also grieving, into Emmy's treatment can facilitate open communication about feelings, information, and support needs. Providers must learn about the family's presenting syndrome and associated psychosocial issues, including prevention, treatment, testing, and reproductive options, to help guide their care and to facilitate informed decision-making.

\section{SUMMARY}

Children in elementary school change rapidly. Much of their psychosocial growth relates to moving from the family environment to the bigger world as they enter school. Normal maturational (and developmental) losses occur as a result of being judged by teachers and peers instead of being unconditionally loved (ideally) in one's home. This means that children experience gains as they navigate these challenges and develop a sense of self-efficacy or may experience a sense of failure if they are unable to negotiate them. These judgments by teachers and peers can be very challenging when a child has a disability or other difference that creates a separation from the peer group. Even young children who move often leave much behind, and for international immigrants, these losses are intensified as they encounter different norms and language. Often they are leaned on by parents instead of the other way around. Schools need to have social workers, school nurses, and trained teachers to give children the support they need.

When children in this age group lose a parent, sibling, pet, or other significant relationship, they have varied abilities to cope. During kindergarten and first grade, they may not have enough verbal facility to process feelings of loss and may withdraw or become hostile or aggressive if the loss is more than they can process. As they grow, they may be less willing to overtly express emotion but have more ability to verbally process the loss and cope by holding on to important memories and linking objects.

Support groups seem particularly helpful for school-aged children. Although these children increase their social connections, they seldom have networks that include others who have experienced the same loss they have unless they are welcomed into such a group. The opportunity to share experiences helps children feel less isolated and ostracized. Support groups also provide an opportunity for validation and shared problem-solving with peers and offer professional support 
to help clarify misconceptions and draw out supportive opportunities. Likewise, bereaved parents find the support of other bereaved parents critical to coping.

\section{DISCUSSION QUESTIONS}

1. If you were working in an elementary school like Sandy Hook, where a shooter came into the school and killed several students as well as himself, how would you guide the school to handle the first 24 to 48 hours? What guidance would you have for the aftermath once students begin to return to the school?

2. How might you work with children who have recently moved to your school who come from non-English-speaking countries and translate for their parents at school meetings?

3. How could you explain to a school administrator why you believe some students' loss and trauma histories impair their academic work?

\section{KEY REFERENCES}

Only key references appear in the print edition. The full reference list appears in the digital product found on http://connect.springerpub.com/content/book/978-0-8261-4964-0/chapter/ch04

Berg, L., Rostila, M., \& Hjern, A. (2016). Parental death during childhood and depression in young adults: A national cohort study. Journal of Child Psychology and Psychiatry, 57, 1092-1098. https://doi .org/10.1111/jcpp. 12560

Boullier, M., \& Blair, M. (2018). Adverse childhood experiences. Paediatrics and Child Health, 28(3), 132-137. https://doi.org/10.1016/j.paed.2017.12.008

Boyd Webb, N., Heath, M., \& Hudnall, G. (2011). Play therapy for bereaved children: Adapting strategies to community, school, and home settings. School Psychology International, 32(2), 132-143. https:// doi.org/10.1177/0143034311400832

Christ, G. H., \& Christ, A. E. (2006). Current approaches to helping children cope with a parent's terminal illness. CA: A Cancer Journal for Clinicians, 56(4), 197-212. https://doi.org/10.3322/canjclin.56.4.197

Goldman, L. (2017). Helping bereaved children in the schools. In R. G. Stevenson \& G. R. Cox (Eds.), Children, adolescents and death: Questions and answers (pp. 153-186). Routledge.

Harvard University Center on the Developing Child. (2019). Three principles to improve outcomes for children and families. https://developingchild.harvard.edu/resources/three-early-childhood-develop ment-principles-improve-child-family-outcomes/

Lichtenthal, W. G., Neimeyer, R. A., Currier, J. M., Roberts, K., \& Jordan, N. (2013). Cause of death and the quest for meaning after the loss of a child. Death Studies, 37(4), 311-342. https://doi.org/10.1080/ 07481187.2012.673533

Pham, S., Porta, G., Biemesser, C., Walker Payne, M., Iyengar, S., Melhem, N., \& Brent, D. A. (2018). The burden of bereavement: Early-onset depression and impairment in youths bereaved by sudden parental death in a 7-year prospective study. American Journal of Psychiatry, 175(9), 887-896. https:// ajp.psychiatryonline.org/doi/pdf/10.1176/appi.ajp.2018.17070792

Rostila, M., Berg, L., Saarela, J., Kawachi, I., \& Hjern, A. (2017). Experience of sibling death in childhood and risk of death in adulthood: A national cohort study from Sweden. American Journal of Epidemiology, 185(12), 1247-1254. https://doi.org/10.1093/aje/kww126

Sheftall, A. H., Asti, L., Horowitz, L. M., Felts, A., Fontanella, C. A., Campo, J., \& Bridge, J. A. (2016). Suicide in elementary school-aged children and early adolescents. Pediatrics, 138(4), e20160436. https://doi. org/10.1542/peds.2016-0436 